\title{
TRAJETÓRIAS DE PESQUISAS EM CONTEXTOS DE COLABORAÇÃO COM PROFESSORES QUE ENSINAM MATEMÁTICA
}

\author{
José Eduardo de Oliveira Evangelista Lanuti'; Klinger Teodoro Ciríaco² \\ 'Universidade Estadual de Campinas -UNICAMP, Programa de Pós Graduação em Educação, Campinas, SP. \\ ${ }^{2}$ Universidade Estadual Paulista - UNESP, Presidente Prudente, SP. E-mail: E-mail: eduardolanuti@hotmail.com, \\ klingerufms@hotmail.com
}

\section{RESUMO}

O artigo apresenta as trajetórias de duas pesquisas de Doutorado desenvolvidas em contextos de colaboração com professores que ensinam Matemática. O objetivo deste trabalho reside em analisar como o formato de organização colaborativo dos grupos em que as pesquisas se desenvolveram contribuiu para a aprendizagem da docência e desenvolvimento de práticas inclusivas no ensino de Matemática. Os autores do presente artigo são os orientadores dos grupos. Ambas as pesquisas analisadas são caracterizadas como pesquisa-ação. Os resultados dos estudos que dialogamos nesse texto apontam indícios da potencialidade do formato de organização colaborativo de ambos os grupos, que viabilizou uma mudança na prática dos professores a partir da comunicação, compartilhamento de experiências e reflexão sobre a própria prática desenvolvida. Os professores participantes passaram a aprender colaborativamente a ensinar Matemática e desenvolver estratégias de ensino na perspectiva da inclusão a partir das pesquisas realizadas.

Palavras-chave: Formação de Professores, Práticas Colaborativas, Ensino de Matemática, Prática Pedagógica, Compartilhamento das Experiências.

\section{RESEARCH ITINERARIES IN CONTEXTS OF COOPERATION WITH MATHEMATICS TEACHERS}

\begin{abstract}
This paper presents the itineraries of two studies on Doctoral level conducted in contexts of cooperation with Mathematics teachers. The purpose of this work is to analyze how the format of collaborative organization of the groups performing the studies contributed to the learning of becoming a teacher and the development of inclusive practices in the teaching of Mathematics. The authors of this article are supervisors of the groups involved. Both studies here analyzed are characterized as action research. The results of the studies we deal with in this paper reveal the potentiality of the format of collaborative organization for both groups, which made it possible a change in the practice of the teachers through the communication, experience sharing and reflection about their own practice. Participating teachers then started to learn collaboratively how to teach Mathematics and devise teaching strategies in the perspective of inclusion based on the studies they had conducted.
\end{abstract}

Keywords: Teacher Education, Collaborative Practices, Mathematics Teaching, Pedagogical Practice, Experience Sharing. 


\section{INTRODUÇÃO}

A formação docente é um assunto que vem sendo muito discutido no meio científico. Muitas vezes a formação inicial do professor é fragmentada e não o auxilia no desenvolvimento de um trabalho pedagógico que vai ao encontro das necessidades do seu cotidiano em sala de aula.

Tardif (2002) afirma que a formação inicial do professor é distante da realidade e que o docente precisa mobilizar os conhecimentos científicos, técnicos e profissionais para ensinar. Conhecimentos, estes, que são progressivos e os professores necessitam de uma formação contínua, que permite a reflexão sobre sua própria prática, já que o processo de construção de saberes não se encerra na formação inicial.

Especificamente em relação aos professores polivalentes que ensinam Matemática, se deve dar uma atenção especial em relação à formação continuada, pois conforme afirmam Curi (2004) e Fiorentini et al (2002) muitos professores concluem cursos de formação sem conhecimentos de conteúdos matemáticos com os quais trabalharão e pesquisas sobre a formação dos professores das séries iniciais do ensino fundamental têm mostrado a existência de lacunas em relação à Matemática, principalmente na formação inicial.

Uma possibilidade para que o professor consiga refletir sobre seu trabalho a fim de construir estratégias de ensino que vão ao encontro das demandas da escola é uma formação em serviço num contexto colaborativo, ou seja, num ambiente que exista uma "[...] base de igualdade de modo a haver ajuda mútua para atingirem objetivos que a todos beneficiem" (BOAVIDA E PONTE, 2002, p. 3).

Acreditamos que em contextos de colaboração é possível compartilhar experiências, problematizar as situações que emergem da prática cotidiana e a partir do olhar múltiplo de um grupo para determinado problema é mais fácil encontrar possíveis soluções para superação das dificuldades dos professores.

Este artigo apresenta a trajetória de duas pesquisas de Doutorado desenvolvidas em contextos de colaboração com professores que ensinam Matemática nos anos iniciais e finais do Ensino Fundamental.

Uma das pesquisas (pesquisa 1) foi defendida este ano no Programa de Pós-Graduação em Educação da Faculdade de Ciências e Tecnologia da Universidade Estadual Paulista - FCT/UNESP ${ }^{1}$ e, a outra, (pesquisa 2) encontra-se em andamento e está vinculada ao Programa de PósGraduação em Educação da Faculdade de Educação na Universidade Estadual de Campinas UNICAMP².

O foco da pesquisa 1 esteve em compreender em que sentido o compartilhamento das experiências e práticas profissionais de professoras integrantes de um grupo colaborativo contribui para a aprendizagem da docência durante os primeiros anos da carreira na perspectiva da pesquisa-ação estratégica.

A pesquisa 2, em desenvolvimento, tem como foco o ensino de Matemática na perspectiva da inclusão, que conforme define Lanuti (2015) é o ensino que valoriza as diferenças, que viabiliza a comunicação entre todos, a participação de todos os alunos sem distinções, a partir de suas possibilidades, e favorece a aprendizagem significativa de Matemática, por meio de situações que contextualizam e dão significado aos conteúdos disciplinares.

Apresentaremos os itinerários dessas pesquisas de Doutorado desenvolvidas em práticas de colaboração com professores que ensinam Matemática em fases distintas da carreira docente,

\footnotetext{
1 Tese intitulada: “Professoras iniciantes e o aprender a ensinar Matemática em um grupo colaborativo" disponível em: http://repositorio.unesp.br/bitstream/handle/11449/139512/ciriaco_kt_dr_prud.pdf?sequence=3

${ }^{2}$ Pesquisa vinculada ao Laboratório de Estudos e Pesquisa em Ensino e Diferença (LEPED) e inserida na linha de pesquisa "Formação de Professores e Trabalho Docente" do Programa de Pós-Graduação (Doutorado em Educação) da Universidade Estadual de Campinas (UNICAMP). Intitulada "Formação Continuada e a construção de práticas colaborativas: o ensino de Matemática na perspectiva da inclusão", financiada pela Fundação de Amparo à Pesquisa do Estado de São Paulo (FAPESP).
} 
pois o objetivo deste trabalho reside em retratar os processos do aprender a ensinar Matemática sob a perspectiva colaborativa em ambientes de compartilhamento de experiências.

\section{METODOLOGIA}

A pesquisa 1 teve como foco responder a seguinte questão: Em que medida a interação entre um grupo de professoras iniciantes contribui para o processo do aprender a ensinar Matemática em um grupo colaborativo?

O trabalho de campo foi desenvolvido com cinco professoras, sendo quatro egressas do curso de Pedagogia e uma da licenciatura em Matemática. Atendendo aos princípios da ética em pesquisa com seres humanos, o processo deste estudo está registrado e aprovado na Plataforma Brasil, inscrito sob o CAAE N. 27854114.2.0000.0021, sob responsabilidade da Universidade Federal de Mato Grosso do Sul - UFMS.

A coleta de dados ocorreu no período de agosto de 2013 a julho de 2015, sendo que nesse período ocorreram mais de 32 sessões em que as docentes registraram suas práticas e partilharam ideias e princípios com o objetivo de organizar o trabalho pedagógico com os conteúdos matemáticos de modo que o compartilhamento das experiências oportunizasse a ressignificação do sentido das aulas durante seus primeiros anos de docência.

A pesquisa 2 tem como objetivo analisar de que forma uma proposta de formação continuada, com formato de organização colaborativo, pode contribuir para que um grupo de professores polivalentes reflita sobre suas ações e construam estratégias de ensino de Matemática que visam à aprendizagem de todos.

O trabalho empírico é desenvolvido com um grupo de 35 professores dos anos iniciais do Ensino Fundamental que ensinam Matemática. Os encontros formativos têm periodicidade semanal e o pesquisador é o formador desse grupo.

A pesquisa foi submetida e aprovada pelo comitê de Ética em Pesquisa da Universidade Estadual de Campinas (UNICAMP), CAAE N. 54026216.6.0000.5404.

Nos encontros, os professores são convidados a relatar suas experiências, dificuldades encontradas para trabalhar determinados conteúdos matemáticos e, a partir da reflexão colaborativa, todos constroem estratégias para ensinar Matemática a partir das potencialidades dos estudantes, dos seus interesses e objetivos.

Os instrumentos utilizados para a coleta de dados são os relatos reflexivos dos professores, os vídeos gravados por eles no desenvolvimento das atividades e os relatos do orientador do grupo. Os dados serão analisados a partir da triangulação desses dados e por meio de categorias que permitirão a análise da mudança de prática dos professores a partir da formação proposta.

De acordo com a dinâmica de encontros realizada e participação dos pesquisadores, que são orientadores do grupo, as duas pesquisas são caracterizadas como pesquisa-ação, por ser um estudo de um determinado contexto social, realizado pelos próprios atuantes desse contexto, com vistas a promover mudanças por meio da aplicação de planos de ação, conforme aponta Silvestre (2008).

\section{RESULTADOS}

Na pesquisa 1, a dinâmica dos encontros com o grupo ocorreu na perspectiva colaborativa e essa característica foi ganhando corpo, forma e conteúdo na medida em que as professoras foram colocadas em movimento de reflexão sobre suas ações nas aulas de Matemática durante suas primeiras vivências no ambiente escolar. Para tanto, recorreu-se a dados provenientes de sessões dos encontros com um grupo colaborativo constituído por professoras da área pedagógica (Pedagogia) e da área específica (Matemática).

A recolha de dados teve, em sua essência, o sentido de mobilizar as professoras iniciantes para processos de aprender a ensinar a partir do compartilhar das experiências e o ressignificar 
das práticas com base na colaboração e interações entre as integrantes do grupo e o professor/pesquisador.

Os resultados emergentes desta experiência possibilitaram perceber, pela tematização da prática, a partir da análise de vídeogravação das aulas das docentes, a necessidade de construir diálogos com os alunos nas aulas de Matemática, dando espaço para o papel da comunicação e da contextualização durante a abordagem dos conteúdos.

Em relação ao episódio escolhido para análise neste texto, referimo-nos especificamente a necessidade de oportunizar o contato dos alunos com o discurso dos termos matemáticos. Em uma aula relacionada ao bloco de conteúdo "tratamento da informação", as professoras puderam refletir sobre o quanto o discurso utilizado para a explanação/explicação do conteúdo envolvia, na aula analisada, um vocabulário pobre em termos matemáticos. Este dado levantou a necessidade do grupo de professoras de incorporar um diálogo mais enriquecido em suas futuras aulas sobre o tema em questão.

Na pesquisa 2, a partir dos conteúdos que devem ser contemplados nas aulas, de acordo com o currículo prescrito adotado pela escola ${ }^{3}$, os professores são convidados a relatar suas dúvidas em relação aos conteúdos específicos e às dificuldades em relação a organização da sala e planejam, em conjunto, as aulas que serão desenvolvidas na próxima semana.

O centro das discussões está também nas necessidades formativas das professoras no que diz respeito à autonomia pra pensar em possibilidades de construção de situações práticas de aprendizagem, para que os conteúdos matemáticos sejam ensinados de forma contextualizada, significativa para os estudantes.

Dentre as principais mudanças na prática dos professores que podem ser observadas com as discussões realizadas nos encontros formativos, está a construção de situações práticas de aprendizagem.

As situações de aprendizagem, segundo a professora E. S do segundo ano "contextualizam os conteúdos e as crianças podem perceber onde usam a Matemática. As discussões no grupo têm me ajudado porque é muito difícil pensar, sozinha, em situações práticas, para que todos os alunos participem das aulas e aprendam do seu jeito. Planejar o trabalho com os outros professores, ouvindo as diferentes opiniões facilita muito!".

A partir das discussões nos encontros formativos, os professores passaram a não utilizar apenas o currículo prescrito como orientador para suas práticas. O grupo, de modo geral tem desenvolvido sua autonomia para planejar e desenvolver ações que vão além do esperado: aulas passeio, debates, rodas de conversa e entrevistas são exemplos de atividades que os professores têm desenvolvido para que todos possam aprender Matemática de forma contextualizada e significativa.

\section{DISCUSSÃO}

Na pesquisa 1, o vídeo analisado pelo grupo tinha como foco a realização de uma leitura de gráfico com crianças de uma turma do terceiro ano do Ensino Fundamental. Pela reflexão crítica no ambiente de colaboração, ficou nítida a necessidade de a professora explorar com as crianças a importância da elaboração do gráfico para comunicar as ideias presentes na atividade: aniversariantes do mês.

O episódio em pauta apresentou um trecho da aula de uma das professoras, momento este em que a mesma já apresentava para seus alunos um roteiro de questões elaboradas previamente sem a participação efetiva de todas no processo de produção e análise de dados, princípios estes que não oportunizaram a ampliação dos conhecimentos e, muito menos, o envolvimento da turma com a tarefa proposta.

\footnotetext{
${ }^{3}$ O currículo prescrito utilizado é o EMAI (Educação Matemática nos Anos Iniciais do Ensino Fundamental), da Secretaria de Educação do Estado de São Paulo/SP.
} 
Estudos de Gama e Nakayama (2016) apontam que é de fundamental importância um processo contínuo na formação de professores, em particular neste estudo dos que ensinam Matemática, pois se espera que esse professor reflita sobre sua prática, tornando-se um investigador de sua ação e se apropriando de novas teorias e recomendações para o processo de ensino e de aprendizagem dos conteúdos matemáticos. Estima-se que, o resultado disso, seja a possibilidade de "[...] contribuir para a compreensão e a construção coletiva de alternativas de solução dos problemas da prática docente nas escolas" (FIORENTINI; NACARATO, 2005, p. 09).

As professoras iniciantes, ao tomarem contato com a vídeogravação, objeto de reflexão do grupo, perceberam a importância do professor construir diálogos, em suas explicações, que sejam melhor elaborados e que contribuam com a ampliação do vocabulário matemático das crianças, pois verificaram a relevância do professor introduzir termos matemáticos desde o primeiro ano do Ensino Fundamental como, por exemplo, trabalhar estatística e probabilidade já introduzindo diferentes tipos de gráficos e histogramas.

Na pesquisa 2, a fala da professora revela que os encontros de formação têm facilitado o processo de planejamento das aulas e reconhece a importância dos momentos de discussão e reflexão sobre as ações desenvolvidas pelo grupo, onde todos se ajudam. Ou seja, o formato de organização colaborativo do grupo, em que todos se ajudam, conforme definem Boavida e Ponte (2002), tem favorecido à reflexão sobre o trabalho pedagógico desenvolvido pelo grupo, para superação das dificuldades encontradas pelos professores.

Além disso, é possível identificar que a professora constatou que na formação para que todos aprendam Matemática é necessário pensar em contextualizar a Matemática para que esta tenha sentido para todos os estudantes, o que vai ao encontro do que defende Lanuti (2015)

\section{CONCLUSÃO}

Ao longo deste texto, nos propusemos a apresentar a trajetória de duas pesquisas de Doutorado desenvolvidas em contextos de colaboração com professores que ensinam Matemática.

No primeiro caso, na pesquisa com professores iniciantes, a experiência compartilhada desencadeou a conscientização de que é preciso trabalhar com os alunos as habilidades de letramento estatístico e isso implica superar o modelo de ensino baseado em atividades mecânicas, em prol do favorecimento de tarefas interdisciplinares, princípios estes possíveis no trabalho com projetos de ensino. Com isso, a possibilidade de compartilhar a sua prática fez com que Paula pudesse apreender elementos teórico-metodológicos para redimensionar a sua atuação em aulas posteriores, ao perceber a necessidade de melhorar a sua performance.

Em relação ao segundo estudo, desenvolvido no campo da formação continuada, tem sido possível identificar que, a partir da formação com formato de organização colaborativo, os professores participantes têm discutido acerca de suas experiências e, sobretudo, sobre suas dificuldades para ensinar os conteúdos matemáticos na perspectiva da inclusão. A colaboração entre os professores da sala de aula comum do ensino regular tem viabilizado o planejamento e desenvolvimento de estratégias que contemplem as diferentes necessidades de todos os estudantes, a partir da mobilização dos diferentes saberes do grupo.

Em suma, as duas experiências dos estudos explorados neste texto apresentam possibilidades e caminhos para a formação permanente dos professores e traz a perspectiva colaborativa como sendo uma possibilidade rica e promissora a ser explorada no ambiente escolar, no sentido de demonstrar o quanto a prática de colaboração pode favorecer tanto a formação quanto o desenvolvimento profissional docente em diferentes fases da carreira. 


\section{REFERÊNCIAS}

BOAVIDA, A. M.; PONTE, J. P. Investigação colaborativa: Potencialidades e problemas. In: GTI (Org.). Reflectir e investigar sobre a prática profissional. Lisboa: APM, 2002.

CURI, E. Formação de professores polivalentes: uma análise do conhecimento para ensinar Matemática e de crenças e atitudes que interferem na constituição desses conhecimentos. 2004. 278 f.Tese (Doutorado em Educação Matemática) - Faculdade de Educação Matemática, PUCSP, São Paulo, 2004.

FIORENTINI, D et al. Formação de professores que ensinam Matemática: um balanço de 25 anos da pesquisa brasileira. Educação em Revista. Dossiê: Educação Matemática. Belo Horizonte, UFMG, n. 36, 2002, p.137-160.

FIORENTINI, D; NACARATO, A. M. (Org.) Cultura, formação e desenvolvimento profissional de professores que ensinam matemática: investigando e teorizando a partir de prática. São Paulo: Musa Editora, 2005.

GAMA, R. P.; NAKAYAMA, B. C. M. S. Rede colaborativa de professores que ensinam Matemática: articulando ensino, pesquisa e extensão. Zetetiké: Revista de Educação Matemática FE/UNICAMP \& FEUFF - v. 24, n. 45 - jan/abr-2016. Disponível em: < http://ojs.fe.unicamp.br/ged/zetetike/article/view/7504/6369>, Acesso em: 25, mai. 2016.

LANUTI, J. E. O. E. Educação Matemática e Inclusão Escolar: a construção de estratégias para uma aprendizagem significativa. 2015. 127f. Dissertação (Mestrado em Educação) - Universidade Estadual Paulista Júlio de Mesquita Filho, Presidente Prudente, 2015.

SILVESTRE, V. S. V. A pesquisa-ação colaborativa na formação universitária de quatro professoras de inglês. 2008. Dissertação (Mestrado em Letras e Lingüística)- Faculdade de Letras, Universidade Federal de Goiás, Goiânia.

TARDIF, M. Saberes docentes e formação profissional. Petrópolis: Vozes, 2002. 